\title{
O Ensino de Linguagem de Programação na Educação Básica Através da Robótica Educacional: Práticas e a Interdisciplinaridade.
}

\author{
Thaise de Amorim Costa ${ }^{1}$, Fábio Cristiano Souza Oliveira ${ }^{1}$, Patrícia da Rocha \\ Moreira $^{1}$, Danielle Juliana Silva Martins ${ }^{1}$. \\ ${ }^{1}$ Instituto Federal de Educação, Ciência e Tecnologia do Sertão Pernambucano - \\ Campus Petrolina (IF-SERTÃO PE). \\ Caixa Postal 56314-520 - Petrolina - PE - Brasil. \\ \{thaise.amorim16, fabiocristianocomp, patdarocha, danielle.juliana.martins\}@gmail.com
}

\begin{abstract}
The teaching of programming languages in basic education is a much debated topic among researchers in the area of computing. To a certain extent, it is due to the benefits that this type of teaching can bring to the students' cognitive development. In this sense, the present work presents an experience report, whose objective was to promote the teaching of computer programming through educational robotics, for primary school students in public schools. The methodology used was based on constructionism, a theory that sees the acquisition of learning through the construction of practical activities. As a result, at the end of the project the students developed two robotic projects using recyclable materials.
\end{abstract}

Resumo. O ensino de linguagens de programação na educação básica é um tema muito debatido entre os pesquisadores da área de computação. Em certa medida, se deve aos beneficios que esse tipo de ensino pode trazer para o desenvolvimento cognitivo dos alunos. Nesse sentido, o presente trabalho vem apresentar um relato de experiência, que teve como objetivo promover o ensino de programação de computadores por meio da robótica educacional, para alunos do ensino fundamental da rede pública. A metodologia utilizada baseou-se no construcionismo, uma teoria que ver a obtenção do aprendizado através da construção de atividades práticas. Como resultados, ao final do projeto os alunos desenvolveram e apresentaram dois projetos robóticos, utilizando materiais recicláveis.

\section{Introdução}

Atualmente o ensino de programação vem crescendo no âmbito das escolas de educação básica, pois os benefícios que esse tipo de ensino proporciona, está ficando cada vez mais evidente. Para Scaico et al (2013), esse tipo de educação permite o desenvolvimento de diversas habilidades que contribuem para melhoria do raciocínio lógico dos estudantes. Entre essas habilidades podemos citar o desenvolvimento de capacidade para solucionar problemas com a sua decomposição, noções de causa e consequência, organização do pensamento, criatividade, entre outros.

O ensino de programação pode trazer inúmeros benefícios para os estudantes. 
Oro et al. (2015) ressalta que o ensino de programação de computadores representa uma alternativa poderosa na qualificação da formação básica das crianças, contribuindo potencialmente, para o processo de ensino e aprendizagem em todas as áreas do conhecimento, uma vez que possibilita o desenvolvimento do raciocínio lógico. Promovendo assim também a interdisciplinaridade, já que o raciocínio lógico está presente em todas as áreas.

Países como Inglaterra, Estados Unidos e Austrália já perceberam sua importância, e incorporaram a linguagem de programação no currículo das séries iniciais de formação escolar. A Inglaterra foi uma das pioneiras a introduzir o ensino de programação e robótica, como aprendizado obrigatório nas escolas. Na Austrália o ensino de programação tornou-se parte do currículo escolar obrigatório para todos os estudantes maiores de 10 anos de idade. Nos Estados Unidos, alguns estados estão tornando obrigatório o ensino de programação e robótica desde a educação infantil até o ensino médio [HAPPYCODE, 2016].

No Brasil existem algumas iniciativas, que buscam disseminar o ensino de linguagem de programação, e mostrar que programar é algo que está ao alcance de todos, como por exemplo, a Hora do Código, um movimento que tem como objetivo aproximar a programação do cotidiano de jovens de todo o Brasil, através de um portal voltado para o ensino e aprendizagem de programação em blocos [COD.ORG, 2015].

Nessa linha, este trabalho vem apresentar experiências com o uso de uma metodologia fundamentada no construcionismo de Seymour Papert ${ }^{1}$, onde foi buscado explorar a criatividade dos alunos por meio de atividades práticas. Essas atividades foram desenvolvidas durante um projeto que teve como objetivo disseminar o ensino de programação de computadores, por meio da robótica educacional, para crianças de 12 a 14 anos do ensino fundamental.

As próximas seções estão apresentadas da seguinte forma, na seção 2 são apresentados os trabalhos relacionados, onde é apresentado um levantamento de projetos que incentivam o aprendizado de programação e robótica. Na seção 3 é descrita a metodologia, e estratégias utilizadas no trabalho. $\mathrm{Na}$ seção 4 são relatados os resultados obtidos, e na seção 5 a conclusão e as discursões finais.

\section{Trabalhos Relacionados}

Ultimamente os trabalhos envolvendo o ensino de linguagem de programação e robótica vem crescendo. Um exemplo desse tipo de iniciativa é o trabalho de Dos Santos (2015), onde alunos de Licenciatura em Computação promoveram o ensino de programação para alunos da educação básica, através de um treinamento em raciocínio lógico, para a Olimpíada Brasileira de Informática.

Já em alguns trabalhos, como o de Monteiro et al. (2016) o ensino de linguagem

\footnotetext{
${ }^{1}$ Disponível em: <http://www.livrosgratis.com.br/ler-livro-online-98059/construcionismo-de-papert-eensino-aprendizagem-de-programacao-de-computadores-no-ensino-superior> Acesso em: mai. 2017
} 
de programação é promovido através da robótica educacional. No trabalho citado, o hardware livre Arduino foi utilizado como alternativa para o ensino de linguagem de programação e Pensamento Computacional, para alunos de um curso do Ensino Médio Integrado.

Outro trabalho relevante é o de Junior et al. (2014), onde o ensino de robótica e lógica de programação é promovido para alunos do ensino fundamental, através da utilização da plataforma Arduino. Neste trabalho, os autores mostraram a viabilidade do ensino de algoritmos por meio da criação de autônomos programáveis, e que não há nenhum empecilho em realizar esses tipos de tarefas com alunos do Ensino Fundamental.

Em Benitti (2009) é apresentado um experimento envolvendo assuntos relacionados com as disciplinas de geografia, matemática e programação de computadores explorados através de atividades com robôs, juntando dois instrumentos de ensino vastamente conhecidos: Lego e Logo.

O ensino de programação através da robótica tem sido muito praticado por pesquisadores. Em relação ao trabalho aqui descrito, o que o diferencia dos trabalhos relacionados citados é a sua metodologia e a proposta de atividades, uma vês que foi buscado trabalhar de forma interdisciplinar, promovendo não só a Ciência da Computação, mas também conceitos de engenharia, matemática, física, eletrônica, arte, e educação ambiental uma temática que foi introduzida durante a montagem de alguns projetos com materiais recicláveis, que serão descritos com mais detalhes na seção a seguir.

\section{Metodologia}

Esta seção apresenta os procedimentos e métodos adotados para execução do curso de programação e robótica ofertado a alunos do Ensino Fundamental da rede pública da região. A turma do projeto foi composta por 10 alunos, que antes de ingressarem nas aulas de robótica participaram durante cinco meses de um projeto de extensão chamado Programadores do Futuro, no qual promovia treinamento em programação de computadores, para a Olimpíada Brasileira de Informática (OBI).

As aulas foram realizadas nos laboratórios de informática do IF Sertão-PE, campus Petrolina, e ministradas por alunos do curso de licenciatura em computação e do curso técnico em informática. A estrutura do curso foi montada da seguinte forma: As aulas ocorriam duas vezes por semana, com duas horas de duração cada encontro, e as atividades do projeto foram divididas em duas etapas, totalizando 60 horas.

Durante a preparação das aulas, foi feito um levantamento sobre as ferramentas que seriam utilizadas durante o curso. E foi decidido utilizar o kit Lego MINDSTORMS durante a primeira etapa, e a plataforma Arduino na segunda etapa do projeto.

O kit Lego MINDSTORMS, foi escolhido por permitir a construção de robôs totalmente autônomos enquanto aborda conceitos de matemática e engenharia, algo positivo já que durante o projeto buscou-se trabalhar a robótica de forma interdisciplinar. Além de que, o kit Lego possui uma estrutura de fácil utilização, sendo 
assim mais adequado para começar a introduzir com os alunos os conceitos de motores, sensores e atuadores.

A escolha pelo Arduino decorreu pelo fato dos alunos já possuírem conhecimentos prévios em linguagem de programação $C$, além de ser uma plataforma que oferece múltiplas possibilidades de uso, podendo assim trabalhar com diversos materiais. Segundo Cardoso e Antonello (2015) o Arduino permite concretizar conceitos abstratos de algoritmos e possibilita que o aluno veja resultados da aplicação desses conceitos na prática por meio de vários componentes eletrônicos.

Já em relação à metodologia utilizada nas aulas, se buscou fundamentar no construcionismo de Seymour Papert. Teoria que defende a importância de "pôr a mão na massa" como um pré-requisito para aprendizagem, ou seja, que o aprendizado ocorre de forma prática. Papert vê o conhecimento de uma forma mais concreta, onde o aprendizado ocorre em um processo de projetar e materializar as ideias [DO ROCIO ZILLI, 2004].

Partindo desse princípio é que durante o projeto foram utilizadas atividades práticas, como por exemplo, a montagem de circuitos eletrônicos e robôs, para estimular os alunos durante o processo de explicação dos conteúdos.

\subsection{Atividades da Primeira Etapa}

A primeira etapa teve duração de $12 \mathrm{~h}$ (quatro encontros), e compreendeu a ambientação em robótica com a introdução de conceitos básicos como motores, sensores e atuadores. Para isso, foi utilizado o kit Lego MINDSTORMS. No primeiro encontro dessa etapa, ocorreu uma apresentação aos alunos sobre a robótica educacional e seu papel no aprendizado deles em relação à programação, já que durante o projeto eles iriam ver, de forma prática, o resultado dos programas desenvolvidos por eles.

Posteriormente foi iniciada a parte práticas das aulas, onde era deito a montagem dos robôs e em seguida feito a sua programação. Algo positivo em relação ao kit Lego é que ele permite que os alunos desenvolvam a programação dos robôs no bloco NXT do próprio Lego. Durante essas aulas os alunos formaram equipes e desenvolveram quatro projetos robóticos com o Lego: o carro robô com sensor de toque, o carro robô com sensor de som, com o sensor de luz e o carro robô com o sensor ultrassônico (Ver Figura 1). Entre as ações que os alunos tinham que fazer os robôs realizarem estavam: Andar e desviar de obstáculos, de acordo com o sensor de cada robô.
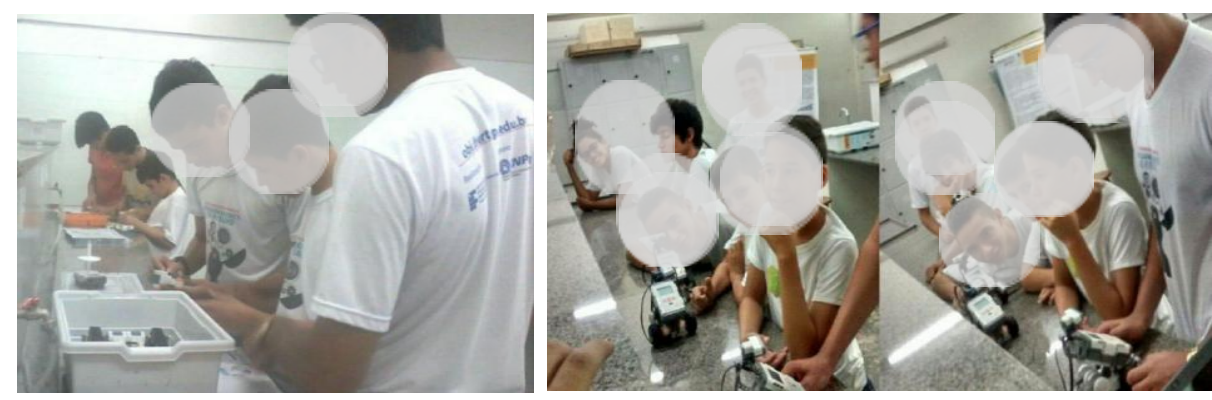

Figura 1. Aulas de Robótica com Lego. 
VI Congresso Brasileiro de Informática na Educação (CBIE 2017)

Anais do XXIII Workshop de Informática na Escola (WIE 2017)

Após finalizar essa fase, a transição para o arduino não foi muito complicada uma vez que os alunos já estavam familiarizados com a linguagem de programação utilizada e com alguns conceitos como sensores e motores.

\subsection{Atividades da Segunda Etapa}

A segunda fase teve duração de $48 \mathrm{~h}$ e caracterizou-se pela a inserção da plataforma Arduino. Nas primeiras aulas desta segunda etapa foi feito uma revisão da Linguagem de Programação $\mathrm{C}$, onde os conteúdos abordados foram: variáveis, estruturas condicionais, estruturas condicionais aninhadas, e estrutura de repetição.

Posteriormente se iniciou as aulas com a plataforma Arduino, onde foram estudados o funcionamento dos seguintes componentes: resistores, transistores, leds protoboard, displays, botões, sensores e montagem dos circuitos, além da programação na IDE Arduino (funções void setup, void loop, pinMode, digitalWrite, delay, bibliotecas, entre outros). Foram ensinados também conceitos de eletrônica, pinos de entrada e saída, pinos analógicos e digitais.

Ao final do projeto foram propostos aos alunos que eles desenvolvessem dois projetos com Arduino utilizando material reciclável, após a sugestão de alguns projetos eles escolheram desenvolver o Jogo Genius ${ }^{2}$ e o carro robô de garrafa (ver figura 2).
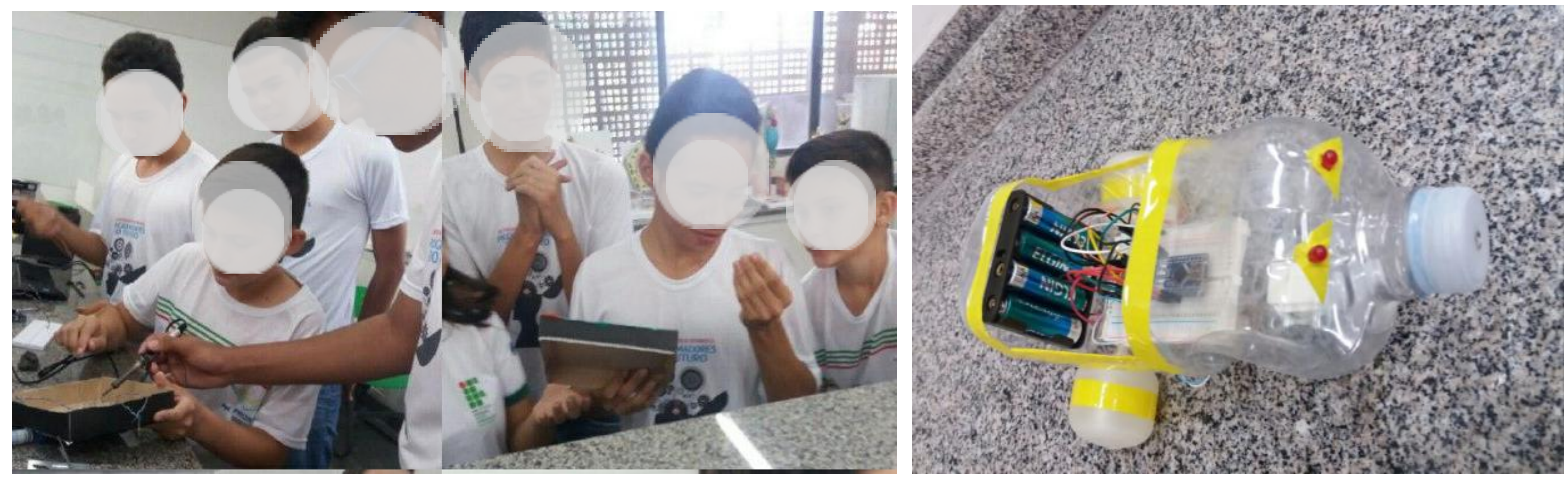

Figura 2. Desenvolvimento do jogo Genius e do carro robô de garrafa.

O Genius é um jogo formado por 4 leds, um de cada cor (amarelo, vermelho, azul e verde), 4 botões para cada led e um speaker para os sons. $\mathrm{O}$ jogo consiste em acertar a sequência em que os leds são acesos. Para o seu desenvolvimento foi utilizado os seguintes materiais: Um Arduino Uno, botões, leds, speaker, protoboard, resistores, caixa de papel e fios de cabos de rede. Durante a montagem houve um grande cuidado com os alunos durante a soldagem, já que eles tiveram que fazer a montagem e soldagem dos circuitos dentro da caixa.

Já para o desenvolvimento do carro robô de garrafa, foram utilizados um

\footnotetext{
2 Disponível em: <https://meetarduino.wordpress.com/2012/05/27/arduino-genius-jogo-da-memoria/>. Acesso em: mai. 2017
} 
Arduino Nano, dois motores DC, um CI L293D, leds, uma protoboard, e um PAC com quatro pilhas para servir de fonte para o carro. Os alunos moldaram uma garrafa cortando-a, e montaram a ligação do circuito de forma que coubesse tudo dentro da garrafa. Para os pneus foram utilizadas tampas de recipientes de plástico. A programação do carro robô foi feita de forma que ele andasse tanto para frente quanto para trás, e girasse várias vezes para a esquerda e para a direita.

O propósito da realização desses projetos foi trabalhar com os alunos conceitos sobre sustentabilidade e educação ambiental, uma vez que durante a produção foram realizadas várias discussões acerca da importância da reutilização de materiais.

\section{Discussão dos Resultados}

Desde os meses iniciais do curso, os alunos se mostraram curiosos com a possibilidade de programar um robô. Durante todo o curso eles foram orientados sobre a importância das habilidades que seriam adquiridas no decorrer das aulas, e o que eles poderiam desenvolver a partir disso, principalmente no âmbito da robótica.

Partindo das ações relatadas podemos afirmar que as atividades com a robótica proporcionaram aos alunos a aprendizagem de conceitos multidisciplinares, como matemática, com o raciocínio lógico exigido nas atividades, física nos cálculos de tempo e velocidade do percurso executado pelo robô. Eletrônica, durante a montagem dos circuitos, e educação ambiental, uma vertente muito importante do nosso trabalho que foi introduzida durante a montagem dos projetos com material reciclável.

Todo o processo de estudo e produção de trabalhos, realizados pelos alunos, resultaram na $1^{\circ}$ Mostra de Programação em Jogos e Robótica do IF Sertão - PE, campus Petrolina. (Ver Figura 3). O evento foi realizado com o intuito de divulgar os trabalhos desenvolvidos pelos alunos durante as aulas.

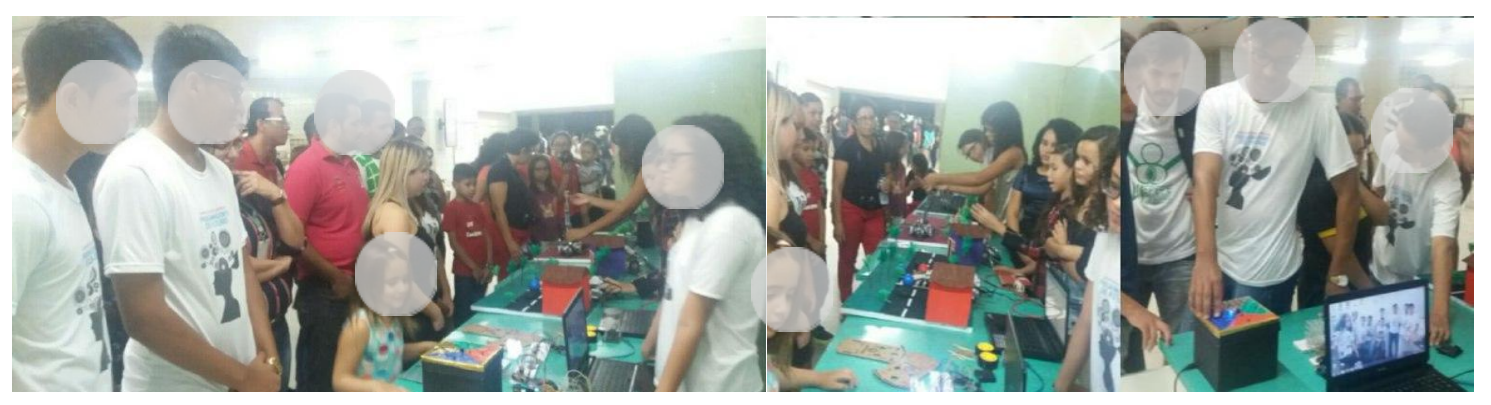

Figura 3. Mostra de Programação em Jogos e Robótica.

A exposição foi aberta aos pais dos alunos e à comunidade. Os alunos apresentaram seus projetos aos visitantes, explicando como foi o seu processo de criação. Nesse momento foi possível observar o aprendizado adquirido pelos alunos, já que eles explicavam com muita clareza o funcionamento de cada projeto. $\mathrm{O}$ jogo Genius foi o destaque da amostra, pois despertava nos visitantes a vontade de jogar e ver quantas sequências eles conseguiam acertar. 
VI Congresso Brasileiro de Informática na Educação (CBIE 2017)

Anais do XXIII Workshop de Informática na Escola (WIE 2017)

O encerramento do evento se deu com a cerimônia de certificação dos alunos (Ver Figura 4), onde foi realizada a entrega de medalhas e certificados de menção honrosa aos trabalhos desenvolvidos.
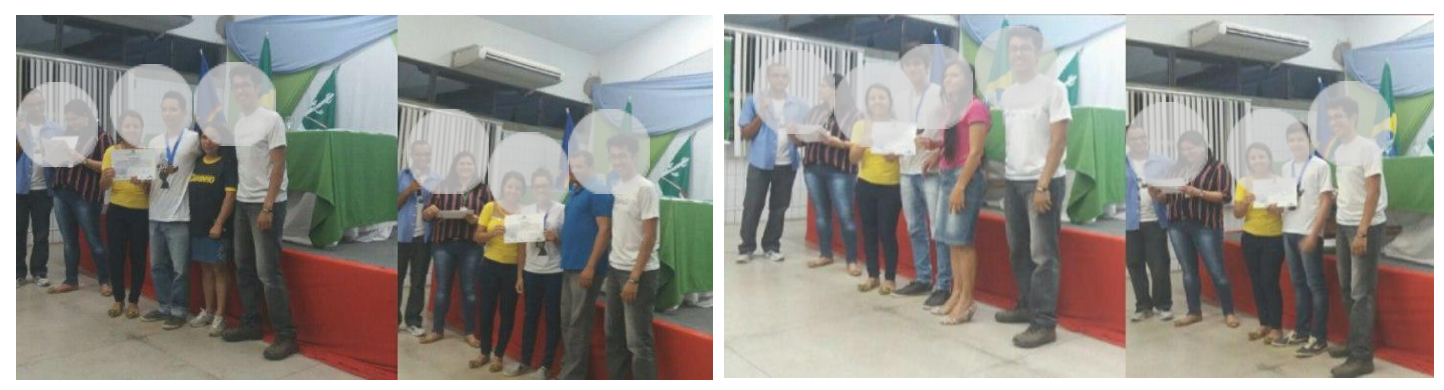

Figura 4. Cerimônia de Certificação.

A reação tanto dos alunos quanto dos pais foi muito positiva, pois essa cerimônia significou o reconhecimento do esforço e dedicação empregado por eles durante as atividades do projeto.

\section{Conclusão}

O presente trabalho teve o objetivo de apresentar, ações desenvolvidas durante um projeto de extensão, bem como os seus resultados para os alunos envolvidos. Vale destacar a oportunidade de inclusão possibilitada a esses alunos, já que os 10 alunos que participaram do projeto não possuíam computadores, e poucos tinham acesso à internet antes de ingressarem no curso (informação relatada pelos alunos).

Algo importante de destacar foi o interesse dos alunos durante as aulas, eles demonstraram bastante entusiasmo durante as atividades de montagem dos circuitos. E toda a experiência adquirida durante o projeto, de certa forma puderam contribuir para $\mathrm{o}$ processo de formação dos alunos, uma vez que eles puderam conhecer melhor a Computação como Ciência e como área de atuação profissional. Foi o que aconteceu com um dos alunos do curso, que se identificou com a área de Computação e conseguiu entrar no Curso Técnico de informática Integrado ao Médio do IF Sertão - PE, campus Petrolina.

Quanto à proposta de metodologia apresentada, os resultados foram positivos, uma vez que a robótica educacional possibilita trabalhar de forma concreta os conceitos abordados em sala, o que reforça a teoria construcionista de que a melhor forma de aprender é realizando atividades práticas.

Em relação à Mostra de Programação em Jogos e Robótica, algo muito positivo foi a reação alegre dos pais ao ver os trabalhos desenvolvidos pelos seus filhos. A cerimônia de certificação também foi muito importante, uma vez que para os pais e alunos isso significou um reconhecimento aos estudos e trabalhos desenvolvidos.

Com isso concluímos que os resultados alcançados por este trabalho contribuíram para o desenvolvimento do ensino de computação na educação básica, de forma lúdica e interdisciplinar, através de atividades práticas. 
VI Congresso Brasileiro de Informática na Educação (CBIE 2017)

Anais do XXIII Workshop de Informática na Escola (WIE 2017)

\section{Referências}

BENITTI, Fabiane Barreto Vavassori et al. Experimentação com Robótica Educativa no Ensino Médio: ambiente, atividades e resultados. In: Anais do Workshop de Informática na Escola. 2009. p. 1811-1820.

CARDOSO, Rogério; ANTONELLO, Sérgio. Interdisciplinaridade, programação visual e robótica educacional: relato de experiência sobre o ensino inicial de programação. In: Anais dos Workshops do Congresso Brasileiro de Informática na Educação. 2015. p. 1255.

COD.ORG. Sobre Nós. Disponível em: 〈https://br.code.org/about〉. Acesso em: mar. 2017.

DO ROCIO ZILLI, Silvana. A robótica educacional no ensino fundamental: Perspectivas e prática. 2004. Tese de Doutorado. Universidade Federal de Santa Catarina, Centro Tecnológico. Programa de Pós-Graduação em Engenharia de Produção.

DOS SANTOS, Erika Raquel Silva; CRISTIANO, Fábio; NETO, Ivaldo Barbosa Da Mota. Raciocínio Lógico e Computação: Descobrindo Estratégias de ensino por meio da Olimpíada Brasileira de Informática. In: Anais do Workshop de Informática na Escola. 2015. p. 266.

HAPYYCODE. O ensino de programação e robótica no Brasil e no mundo. Disponível em: <http://www.happycode.com.br/ensino-de-programacao-erobotica/>. Acesso em: mai. 2017.

JUNIOR, A. DE L. C. et al. Utilização de robótica livre com dispositivos móveis no ensino de lógica de programação para alunos do Ensino Fundamental. XIX Conferência Internacional sobre Informática na Educação - TISE 2014. Anais...2014.

MONTEIRO, David et al. Uma Experiência do Uso Do Hardware Livre Arduino no Ensino De Programação De Computadores. In: Anais do Workshop de Informática na Escola. 2016. p. 51.

ORO, Neuza et al. Olimpíada de Programação de Computadores para Estudantes do Ensino Fundamental: A interdisciplinaridade por meio do Software Scratch. In: Anais do Workshop de Informática na Escola. 2015. p. 102.

QUEIROZ, Rubens Lacerda; SAMPAIO, Fábio Ferrentini. DuinoBlocks4Kids: Um ambiente de programação em blocos para o ensino de conceitos básicos de programação a crianças do Ensino Fundamental I por meio da Robótica Educacional. Anais do CSBC, p. 2086-2095, 2016.

SCAICO, P. D. et al. Ensino de Programação no Ensino Médio: Uma Abordagem Orientada ao Design com a linguagem Scratch. Revista Brasileira de Informática na Educação, v. 21, n. 02, p. 92, 2013. 